\title{
MANUEL REVUELTA GONZÁLEZ: BIÓGRAFO DE LA HISTORIA
}

\author{
JOSÉ GARCÍA DE CASTRO VALDÉS, SJ ${ }^{1}$
}

\begin{abstract}
RESUMEN: Entre los grandes temas de estudio que ocuparon la trayectoria académica del Prof. Manuel Revuelta no encontramos la biografía como tal; Revuelta no hizo de ningún personaje en particular el centro de su investigación. No obstante, son numerosas las veces que el historiador se detiene a presentar diversos protagonistas (principalmente jesuitas) que han influido en el contexto histórico objeto de su atención y análisis. Entendiendo biografía en un sentido amplio (bio-grafía) este artículo se centra en el "Revuelta biógrafo» para conocer tanto a los personajes biografiados como el modo peculiar de mirar $y$ analizar que Revuelta desarrolló a la hora de presentar a sus "héroes callados».

Palabras Clave: Biografía; Compañía de Jesús; Iglesia Española Contemporánea.
\end{abstract}

\section{Manuel Revuelta González: Biographer of History}

ABSTRACT. Among some of the most important topics developed by Professor Manuel Revuelta in his academic itinerary, we do not find biography as such. Professor Revuelta did not place any particular character in the center of his research. His approach was rather one of identifying those historical characters (mainly Jesuits) who most influenced the historical context that he was exploring. Understanding biography in its widest meaning (bio-graphy), this article focusses on "Revuelta as biographer» both to know the historical persons he studied as well as to grasp the rather original historical analysis which he conducted and by which he presented his "silent heroes».

KEY WORDS: Biography; Society of Jesus; Spanish Contemporary Church.

\section{INTRODUCCIÓN}

Como en todo historiador de largo y fecundo recorrido académico, encontramos en la producción literaria de Manuel Revuelta obras de muy diversa intención, finalidad y envergadura ${ }^{2}$. Revuelta fue un historiador riguroso

\footnotetext{
1 Facultad de Teología (U.P. Comillas).Correo electrónico: josegc@comillas.edu.

2 Disponemos de la bibliografía preparada por el mismo Manuel Revuelta (Revuelta, 2017b) organizada según los siguientes apartados: 1. Libros (nn. 1-20). 2.
} 
que supo integrar en su dedicación a la ciencia histórica la investigación científica de más alto nivel con la divulgación pedagógica, fruto de las numerosas peticiones que de sitios muy diversos recibía para ilustrar con conocimiento (no carente de humor discreto) celebraciones de centenarios, aniversarios, homenajes...

Rara avis en su hábitat, Revuelta encarnó la paradoja del «académico humilde». Como profesor y maestro, su vida discurrió tanto por congresos de reconocido prestigio científico como por escenarios «de más baja condición» siempre con el fin de compartir el saber e ilustrar deleitando a públicos de naturaleza muy diversa. La pluma de Revuelta fluía fácil por muy diversos géneros literarios: monografías densas y físicamente "pesadas», la edición crítica de textos, el análisis de períodos y conflictos históricos, la historiografía, necrológicas, artículos de diccionario, prólogos, recensiones. Entre tanta producción y de tan diverso tipo encontramos también la biografía como una contribución muy significativa en su extensa producción literaria.

El objetivo de estas páginas es sacar a la luz esta dimensión más desconocida del historiador y con ella a los personajes históricos biografiados, la mayor parte ensombrecidos y en silencio, pero todos arquitectos de la España que les tocó vivir. Tras un breve acercamiento a las grandes obras de Revuelta que ofrecen un contexto histórico-cultural-eclesiástico para sus biografiados (1) y tras detenernos para precisar el concepto de biografía que en este trabajo manejamos (2), pasaremos a presentar la biografía en Revuelta (3) para acercarnos finalmente a sus biografiados. Comenzamos, pues, adentrándonos en el contexto histórico de la España contemporánea del que Revuelta constató profundo y crítico conocimiento en lo que he denominado su opera maior.

\section{OPERA MAIOR, EL NECESARIO CONTEXTO PARA LAS BIOGRAFÍAS}

Acercarse, aunque sea en pequeña y breve medida, a la vida de un personaje histórico requiere un sólido y previo conocimiento del contexto histórico (social, político, económico, eclesiástico, cultural) que le dio significado e identidad. En el caso de Revuelta, este saber quedó expuesto en los libros de descripción, análisis y valoración histórica de lo que fue principalmente

Libros colectivos (nn. 21-87). 3. Artículos en revistas (nn. 88-207). 4. Prólogos (nn. 208-238). 5. Artículos en diccionarios (nn. 239-286). 6. Recensiones (nn. 287-482). 
el tiempo y el lugar que ocuparon el centro de gravedad de su trayectoria académica: la España del siglo XIX y primera mitad del siglo $\mathrm{XX}^{3}$.

Entre las obras que podríamos considerar de mayor relevancia científica destacan, en primer lugar, los libros publicados en los comienzos de su labor investigadora allá por la década de los setenta. Ahí encontramos libros como la Política de los liberales en el siglo XIX. Trienio constitucional (Revuelta, 1973) o, La exclaustración (1833-1840), (Revuelta, 1976; reed. 2010) considerado ya un clásico entre las aportaciones a la historia de la España contemporánea. Además, Revuelta colaboró en la gran Historia de la Iglesia en España con su largo capítulo «La Iglesia española ante la crisis del Antiguo Régimen (1080-1833)» (Revuelta, 1979).

Pocos años después, en la década de los ochenta y comienzos de los noventa vieron la luz dos enormes obras (tanto en extensión impresa como en profundidad y rigor metodológico) que vinieron a consolidar, si todavía era necesario hacerlo, la cualidad científica de Revuelta. La primera era una gran Historia de la Compañía de Jesús en la España contemporánea ${ }^{4}$ en tres volúmenes (Revuelta, 1984, 1991a y 2008) y la segunda, la recuperación de documentos de gran interés para el conocimiento de una época de Europa y, en especial de la Iglesia y de la Compañía de Jesús: Las Memorias del P. Luis Martín, con sus 2195 páginas, recogen la documentación del vigésimo cuarto padre general de la Compañía de Jesús, y gran impulsor de los estudios históricos ad intra de la institución jesuítica, como tendremos ocasión de comprobar (Eguillor, Revuelta y Sanz de Diego, 1988).

Todavía entre su opera maior, encontramos una historia de los colegios jesuíticos en la España contemporánea (Revuelta, 1998b), dos monografías sobre la historia de la Iglesia española (Revuelta, 2005 y 2017a) y una aproximación a diversos puntos relevantes en la historia de la Compañía de Jesús (Revuelta, 2006a).

3 Digo «centro de gravedad» para poder así incluir numerosas publicaciones que trascienden los límites tanto del espacio como del tiempo al que me he referido; pero se trata de obras que podríamos llamar "periféricas» y que en alguna medida vienen a complementar lo que fue el centro de atención primero de la vida intelectual de Revuelta.

4 Se trata de un total de 3.581 páginas (Tomo I: 1227; Tomo II: 1365; Tomo III: 989) a lo largo de las cuales Revuelta reconstruye a partir del sólido apoyo en fuentes primarias la compleja presencia de la Compañía de Jesús en la España de finales del XIX y comienzos del XX. Una obra de obligada consulta y referencia no sólo para adentrarse en la historia de la institución jesuítica sino también en la historia de la Iglesia y de España de la época. En adelante: LCJEC seguido de tomo y número de páginas. 


\section{BIÓGRAFO, BIOGRAFÍAS, BIOGRAFIADOS}

De entre los numerosos géneros literarios por los que se encaminó el profesor Manuel Revuelta para encauzar su saber, encontramos en el de la biografía como una manera de adentrarse en una época, en un contexto e incluso en encrucijadas o conflictos históricos a través de los ojos, el pensamiento o la obra de alguno de sus protagonistas. Para poder considerar a estas obras indirecta o implícitamente biográficas, tomamos aquí el término biografía en un sentido lato, muy cercano al de su primer significado que la misma etimología nos evoca: la escritura (grafía) sobre la vida (bios).

\subsection{REVUELTA Y LAS BIOGRAFÍAS}

Aunque la historia se construya integrando las grandes líneas de pensamiento político, de los movimientos sociales, de las corrientes culturales o de los grandes vaivenes de la economía, antes o después, todo historiador acaba topándose con los personajes históricos que están detrás de estos grandes motores del tiempo. El historiador se descubre entonces frente a un rostro, un nombre, una personalidad con su contexto histórico, sus condicionantes y posibilidades, incluso con su carácter y peculiaridad psicológica que tantas veces han influido en la toma de una u otra decisión y que han terminado por conducir la historia por esta o aquella dirección. Antes o después, por tanto, el personaje histórico se convierte en compañero de camino de la investigación histórica y entonces, comenzamos a hacer «biografía».

Entre las grandes obras de Revuelta no encontramos ninguna biografía en el sentido estricto y riguroso del término. No podemos afirmar que Revuelta haya sido el historiador definitivo de tal o cual protagonista de la historia al modo en que, por ejemplo, Geoffrey Parker se centró en Felipe II (Parker, 2015) o Georg O. Schurhammer en Francisco Javier (Schurhammer, 1992), obras que demandaron la atención de toda una vida siguiendo y persiguiendo al biografiado hasta sacar a la luz la pretendida «biografía definitiva» (¿será eso posible?).

Pero como podrá descubrirse con facilidad en estas páginas, Revuelta se aproximó a las vidas de no pocos personajes históricos con intenciones y finalidades muy diversas. Desde responder a la invitación de algún evento cultural en algún lugar de la geografía española (Revuelta, 2015a), hasta evocar desde el afecto del compañero y el rigor del colega a un amigo fallecido (Revuelta, 1987), pasando por la participación en homenajes a jesuitas 
significativos (Revuelta, 2003) o la amplia colaboración en enciclopedias o diccionarios biográfico y temáticos.

\subsection{Fuentes, MÉtodo y ESTILO}

El amplio número de recensiones que Revuelta publicó da cuenta del interés con que seguía las novedades que iban apareciendo sobre su ámbito de investigación. Sobrevolando sus páginas, da la impresión de que conocía todo y lo había leído casi todo. Pero Revuelta no fue nunca un investigador de bibliografía secundaria. Leyendo las biografías publicadas en los diccionarios y las que aparecen diseminadas en La Compañia de Jesús en la España contemporánea, el lector percibe espontáneamente que Revuelta permanece en contacto directo, inmediato y constante con las fuentes primeras, publicadas o inéditas. Revuelta fue historiador de dato verificable y verificado y su historia avanza línea a línea descansando sobre la sólida verdad de la fuente de archivo (otra cosa es que lo que diga el documento de archivo precise ser interpretada y valorada críticamente). Aunque Manuel Revuelta estuviera paseando, comiendo o durmiendo, una dimensión no pequeña de su espíritu vagaba silenciosamente por la sala de alguno de sus numerosos archivos, su natural «hábitat académico».

Así, es frecuente encontrar en la bibliografía de sus voces de diccionario frecuentes referencias a Monumenta Historica Societatis Iesus, o a los documentos originales de instituciones o personas biografiadas (cartas, diarios, memoriales). Para las biografías de jesuitas Revuelta ofrece en todo momento la documentación pertinente del archivo oportuno (AHL, APLeón, APT, APTarr, ARSI, AUPC... $)^{5}$. Acude con frecuencia a las Noticias de las Provincias, información interna de la Orden que periódicamente se publicaba y se distribuía por todas las comunidades de España. Otra fuente de primera mano la constituyen las llamadas Cartas edificantes a través de las cuales se divulgaban noticias curiosas de las diferentes provincias que pretendían transmitir de manera constructiva y positiva, proyectos, ministerios e inicia-

5 Archivo Histórico de Loyola, Archivo de la Provincia de León, Archivo de la Provincia de Toledo, Archivo de la Provincia Tarraconense, Archivum Romanum Societatis Iesus, Archivo de la Universidad Pontificia Comillas. El profundo y minucioso conocimiento que Revuelta tenía de los archivos jesuíticos y la facilidad con la que se manejaba entre sus legajos de cartas y otros manuscritos se muestra de manera admirable en su gran obra La Compañía de Jesús en la España Contemporánea (cf. nota 3). Basta fijarse en las notas a pie de página de alguna de las más de 3.000 páginas para darse cuenta del sólido fundamento «archivístico» de la información que Revuelta va ofreciendo. 
tivas de los jesuitas en misiones muy diversas ${ }^{6}$. Revuelta utiliza con frecuencia y también con prudencia esta fuente que no deja de ser documentación de primera mano ${ }^{7}$. Otra fuente habitual en la mesa de trabajo de Revuelta han sido los Catálogos de las provincias de la Compañía de Jesús, cuyo origen se remonta a los inicios de la Orden ${ }^{8}$. Recuerdo alguna conversación con Revuelta sobre este punto; para él los catálogos eran fuente básica y de «primera necesidad» para reconstruir los itinerarios y las vidas de los jesuitas. Él los manejaba con soltura y maestría ${ }^{9}$.

En cuanto al modo de organizar sus biografías, Revuelta sigue un modelo parecido en todas ellas. Tras una breve alusión al origen familiar, la infancia o adolescencia del biografiado, Revuelta reconstruye con detalle el itinerario del jesuita, por lo general bastante complejo sobre todo durante los años de la larga formación: estudios, experiencias, ordenación sacerdotal, viajes. A continuación, se centra en la «vida apostólica», en los ministerios principales desarrollados y las aportaciones a la sociedad de la época. Si el artículo lo permite, puede incluir alguna cita de alguna obra, carta... En los artículos publicados en el Diccionario Histórico de la Compañía de Jesús (DHCJ) (O’Neill y Domínguez, 2001) Revuelta suele incluir algunas líneas finales que sintetizan el perfil psicológico y/o espiritual del biografiado incluyendo en algunos casos el testimonio de algún contemporáneo o añadiendo su propia síntesis extraída del conocimiento ya adquirido de su personaje. Suele ser un comentario final benévolo que trata de ofrecer una imagen amable del jesuita, como podremos ir mostrando más adelante.

La mayor parte de estas biografías aparecen publicadas de manera visible en dos grandes obras: el Diccionario Histórico de la Compañía de Jesús

6 La biblioteca de la Universidad Pontificia Comillas conserva varias colecciones de este tipo de correspondencia. Cito solo: Cartas edificantes de la Provincia de Castilla. Oña: Imprenta privada del colegio 1912. Se conservan las de la pronvicia de Aragón (1912), de Toledo (1913), de Colombia (1925), México (1896)...

7 Sobre todas estas fuentes de tipo de correspondencia en la estructura interna de la Compañía de Jesús puede verse: Aa (2001). Correspondencia. En DHCJ, I, 965-969.

8 El Catálogo es la publicación anual de cada provincia de la Compañía de Jesús en la que se presenta según un orden común para todas, las comunidades, instituciones y jesuitas vinculados a cada provincia. Ya la primera Compañía de Jesús [Constituciones 676] pergeñó el primer modelo de Catálogo y fueron evolucionando hacia lo que actualmente son. Los primeros más parecidos a los actuales se imprimieron en Austria (1715) y en Polonia (1718). Cf. Aixalá, J. 6. Catálogos, En DHCJ I, 967 (s.v. Correspondencia).

9 Sirvan como ejemplo, entre otros muchos posibles, las notas 167-181 de LCJEC II, 598-599. 
$(D C H C J)$ y en el Diccionario Biográfico Español (DBE), (Olmedo y Aldea, 2009-2013) ${ }^{10}$.

La extensión de las biografías es diversa. Revuelta varía más en los artículos del $D H C J$ que en los del $D E B$. En el primero encontramos la entrada más breve de diecisiete líneas (unas 150 palabras) sobre García Leal (Revuelta, 2001a) junto a la más larga de 75 líneas (aprox. 600 palabras) sobre el P. de La Torre (Revuelta, 2001b). Por su parte, las voces del DBE son más homogéneas en su extensión y siguen la forma anteriormente expuesta. Destaca la entrada sobre Sisinio Nevares con 1713 palabras (Revuelta, 2013a), cuando la mayor parte de las voces están entre las 657 del artículo sobre Luis Fernández Martín (Revuelta, 2011a) y las 840 de Mariano Cortés (Revuelta, 2011b).

\section{BIÓGRAFO DE LA COMPAÑÍA DE JESÚS}

Si exceptuamos algunas publicaciones de carácter antropológico cultural, en su mayor parte relacionadas con las tierras, caminos, personajes y tradiciones de su Palencia natal ${ }^{11}$, la práctica totalidad de la producción literaria de Revuelta está relacionada, directamente, con la historia de la Iglesia. Es muy difícil espigar alguna obra en cuyo título no se aluda de una u otra manera a algún punto relacionado con la vida de la Iglesia: sus tradiciones, sus protagonistas, sus instituciones, congregaciones... La vocación académica de Revuelta tuvo un objetivo primero y fundamental que fue al mismo tiempo el sólido cimiento de toda su obra: dar a conocer el pasado reciente de la Iglesia católica en España.

\subsection{LAS BIOGRAFías DE LOS JESUITAS}

Dentro de esta «biografía de la Iglesia» contemporánea tienen un papel preponderante las biografías de jesuitas. De los 63 personajes que hemos considerado como biografiados ${ }^{12}$ latamente entendido, 58 pertenecen a la

\footnotetext{
10 Todas las referencias a las dieciséis entradas que Revuelta tiene en este diccionario están tomadas de la versión electrónica: http://www.dbe.rah.es

11 Cf. Revuelta, M. (2017b). Publicaciones no: 5, 17, 24, 37, 39, 54, 63, 125, 133, 155. Pueden verse en este mismo volumen las contribuciones de Antonio Astorgano, «El palencianismo historiográfico de Manuel Revuelta» y de Eusebio Gil, «Manuel Revuelta. Palentino universal. Historiador arraigado en su tierra natal».

12 Remito a la tabla que ofrezco en las páginas finales de este trabajo.
} 
Compañía de Jesús y tan solo 5 no son jesuitas, pero pertenecen a ámbitos de la Iglesia católica ${ }^{13}$. Esta enorme desigualdad (jesuitas/no jesuitas) tiene su lógica y sentido. Revuelta fue, en gran medida, un historiador de su propia congregación que asumió con competencia y fidelidad asombrosas la misión recibida desde su Orden ${ }^{14}$. Como jesuita disfrutó de los privilegios que suponía el fácil acceso a los archivos y bibliotecas (unos más abiertos y otros más privados) de la Compañía tanto en España como en otros lugares de Europa.

Ahora bien, aunque la mayor parte de las biografías aparecen publicadas en los diccionarios arriba mencionados, una vez superado el «vértigo académico» que produce asomarse a la gran obra de La Compañía de Jesús en la España contemporánea (LCJEC $)^{15}$, el lector va topándose en ella con numerosas biografías diseminadas con magistral acierto a lo largo de las 3.581 páginas que construyen esta impresionante obra. En casi todos los casos, cada una de estas biografías invisibles podría formar por sí misma una entrada en algún diccionario histórico de la España contemporánea. Revuelta introduce estas pequeñas biografías, sobre todo al exponer el gobierno de las provincias. Dedica a cada provincial una, dos, tres páginas que sintetizan magistralmente estos tres aspectos de la persona: las circunstancias locales, el perfil psico-espiritual y las principales aportaciones a la provincia durante su período de gobierno.

Las dimensiones de este trabajo no nos permiten detenernos en estas biografías implícitas o invisibles. En la tabla final añadimos su referencia para visibilizarlas como valiosa aportación al género biográfico desarrollado por Revuelta (Revuelta, 1984 y 1991).

\subsection{LOS BIOGRAFIADOS}

Seguimos en esta tipología las «palabras clave» que aparecen en los Diccionarios en los que la mayor parte de los artículos han sido publicados.

13 Por ahora sólo los enumeramos: Teresa de Jesús (1515-1582), Bonifacia Rodríguez de Castro (1837-1905), Jesús San Martín Payo (1906-1992), Judas José Romo y Gamboa (1799-1855) y fray Miguel de Santander (1744-1831).

14 Fue el provincial Ferrer Pi quien en 1979 le encomendó la tarea de escribir la historia de la Compañía de Jesús en la España contemporánea.

15 Revuelta, M. (1984, 1991a y 2008). Revuelta reconstruye la historia articulando el criterio cronológico (vol. I: 1868-1883; vol. II: 1884-1906 y vol. III: 1868-1912) con el geográfico, desplegando la información según lo que acontecía en las provincias de Castilla y Aragón. Una vez dentro de cada provincia, cuando el discurso lo permite, fija su atención en las diversas instituciones de cada una de ellas: colegios, residencias, centros de formación. 


\section{a. Santos y beatos}

Revuelta no fue un hagiógrafo. Como historiador, no le interesó tanto detenerse en comentar o presentar vidas ejemplares o edificantes cuanto analizar problemáticas de fondo o episodios que pudieran afectar a la vida de la Iglesia o de la Compañía de Jesús. Aun así, encontramos algún trabajo dedicado a santos/ as.

+ En primer lugar, tanto por orden cronológico como por orden de importancia topamos con san Ignacio de Loyola. Encontramos cuatro títulos donde Revuelta se detiene en la vida del fundador de la Compañía de Jesús. En 1992 colaboró con Historia 16 con «El fundador de la Compañía de Jesús» (Revuelta, 1992); en 2006 (año de celebraciones de centenarios ignacianos ${ }^{16}$ ) publicó «Influencias de san Ignacio en la Iglesia» (Revuelta, 2006b) y «La vida de Ignacio. Fundamento de la historia de la Compañía» (Revuelta, 2006c). Siete años después apareció «Ignacio de Loyola: una vida al servicio de la Iglesia» (Revuelta, 2013b). Como se puede ver, son aproximaciones de carácter general y de intención altamente divulgativa, otro género literario que Revuelta manejaba con maestría. Junto con Ignacio, encontramos una única referencia a San Francisco Javier en un artículo de semanario religioso compartido dedicado al misionero universal y al fundador de la Orden (Revuelta, 2011c) ${ }^{17}$.

+ Junto con Diego Luis de Sanvitores y José María Rubio, un 6 de octubre de 1985, subió a los altares como beato, el Hermano Francisco Gárate (Loyola 1857-Bilbao 1929); Revuelta prologó el libro de Ignacio Echániz El Hermano finuras, como era conocido este jesuita que dedicó gran parte de su vida a servir como portero en la recepción de la Universidad de Deusto (Revuelta, 1993).

+ El P. José María Rubio Peralta (Dalías [Cádiz] 1864- Roma 1929) era conocido como «el apóstol de los pobres de Madrid». Fue canonizado el 4

${ }^{16}$ Ese año se conmemoraron los 500 años del nacimiento de San Pedro Fabro y San Francisco Javier, los primeros compañeros de Ignacio de Loyola que compartieron años de estudios en la parisina universidad de La Sorbona y los 450 años del fallecimiento de Ignacio de Loyola (1556).

17 Hubiera sido interesante disponer de una vida de san Ignacio preparada por Revuelta. Aunque el siglo XVI no era su época de estudio, su amplio conocimiento de las fuentes ignacianas, del mismo san Ignacio y de las biografías que sobre él se han ido publicando las últimas décadas, le autorizaban para redactar con competencia una vida para un público amplio y deseoso de conocer a Ignacio. Lo original de esta obra estaría no tanto en la erudición o en la cantidad de información aportada (pues para eso ya hay otras muy buenas biografías) cuanto en la perspectiva, el tono y el personal estilo que Revuelta habría sabido darle. 
de mayo de 2003 en Madrid junto al. P. Enrique Ossó, la Madre Genoveva Torres y la Madre Maravillas. Con ese motivo, la Provincia de Toledo de la Compañía de Jesús organizó un Homenaje a este jesuita recién canonizado e invitó a Revuelta a que presentara a este singular personaje de Madrid, andariego por las zonas más pobres de la capital en una época muy familiar para Revuelta: «Un hombre santo en una España difícil» (Revuelta, 2003).

+ Contemporáneo del P. Rubio, fue el beato Narciso Basté Basté (San Andrés del Palomar [Barcelona] 1866-Valencia 1936). En su artículo en el Diccionario Biográfico Español Revuelta le califica de «Educador de la juventud, beato y mártir». Entregó gran parte de su vida al Patronato de la Juventud obrera en Valencia. Tras ser detenido y liberado cuatro veces, fue fusilado el 15 de octubre de 1936 (Revuelta, 2011d).

\section{b. Profesores}

Otro grupo de biografiados pertenece al ámbito de la educación, tan querido para Revuelta. Encontramos siete jesuitas que vienen definidos en las etiquetas de los diccionarios como «Profesor». Por orden cronológico, son los siguientes:

+ Nicolás de Bobadilla (Bobadilla del Camino / Palencia 1509-Loreto 1590). Revuelta sentía una especial simpatía y hasta devoción por este jesuita cofundador de la Compañía de Jesús. El hecho de ser palentino y haber cargado durante más de cuatro siglos con una cierta etiqueta de jesuita díscolo y rebelde despertaba en Revuelta el ánimo de salir en su defensa y rehabilitarle de alguna forma. Cuando le propuse leer una tesina de licenciatura sobre Bobadilla para que nos ofreciera su cualificada opinión de cara a su posible publicación, le hizo gran ilusión leer el manuscrito de Cristóbal Pasini. Tras ofrecer unas lúcidas observaciones para mejorarlo y dar su parecer positivo para su publicación, también redactó el sabroso prólogo (Revuelta, 2016).

+ De Manuel Gil Sáenz (Madrid 1794-Fiésole /Florencia 1880) dice Revuelta: "ha pasado a la historia como eterno superior y testigo de un siglo de vicisitudes» elogiado por el P. General Beckx como «hombre piadoso, fiel en su cargo, amante de la Compañía» (Revuelta, 2001c, 1730).

+ Felipe Gómez (Montánchez / Cáceres 1811-Madrid 1870) fue profesor en el colegio Imperial de Madrid y también en Salamanca y León. Hombre de gobierno "emprendedor, sacrificado y cordial [...] tenía más de madre que de padre» (Revuelta, 2001d, 1772).

+ A Carlos Maldonado (Campo de Criptana / Ciudad Real 1816-Woodstock / Maryland 1872), como a tantos jesuitas de estos años, le tocó discurrir 
por no pocos sitios debido a la inestable situación política en España. Hizo parte de su Teología en Nápoles, enseñó en Benvento hasta que en 1846 fue enviado al Seminario de Fordham (Nueva York). Profesor en Loyola y Francia para terminar sus días como profesor en Woodstock. «Dotado de mente vigorosa y arrolladora simpatía, M[aldonado] fue un profesor profundo y atractivo que dejó un recuerdo imborrable entre sus alumnos» (Revuelta, 2001e, p. 2.483).

+ La vida de Isacio María Morán (Rodilana / Valladolid 1879-Oña / Burgos 1858), "carece de hechos llamativos», dice Revuelta. Toda una vida dedicada a la docencia de la Teología Moral y a la dirección espiritual de los jóvenes jesuitas. Revuelta dice que él mismo se definía como «tapagujeros». «Se dedicó a los estudiantes con inmensa bondad y atinados consejos [...] hombre ejemplar, austero, amante de la CJ» (Revuelta, 2001f, p. 2.738).

+ Por último recordamos al profesor Enrique Basabe (Castro Urdiales / Cantabria 1893-Salamanca 1977), gran pedagogo, humanista y profesor de lenguas y cultura clásica (Homero y Horacio). "Completó sus actividades docentes con una gran dedicación a los sectores más necesitados de Salamanca, hacia los que se sentía inclinado por su carácter abierto y afición a las obras sociales» (Revuelta, 2011e).

Hasta aquí, los biografiados pertenecen al período histórico propio del estudio de Revuelta, en la España contemporánea.

+ Junto a estos, encontramos también las páginas dedicadas a Gregorio (Goyo) Ruiz que rezuman cercanía y amistad profundas. Están escritas con el corazón de una memoria que no sólo recuerda a un colega tempranamente fallecido (Goyo murió con 49 años) con una amplia producción científica y divulgativa sobre temas bíblicos (Gil, 1987), sino que plasma en cada una de las líneas el afecto profundo por un amigo al que se ve que «conocía internamente» desde la infancia (Revuelta, 1987 y $2001 \mathrm{~g}$, p. 3.439).

\section{c. Científicos}

Otro pequeño grupo de biografiados configuran este subapartado de jesuitas científicos vinculados más bien a las ciencias humanas (humanidades) que a las ciencias positivas. Entre ellos encontramos los siguientes.

\section{c.1. Historiadores}

Revuelta perteneció a una fecunda generación de historiadores jesuitas españoles que ejercieron la docencia y la investigación a un alto y reconocido 
nivel académico ${ }^{18}$. Con alguno de ellos, compartió durante largos años lugar de trabajo y algún gran proyecto de investigación. Revuelta escribió el In memoriam o la necrológica de, al menos, tres de sus queridos compañeros.

+ A Quintín Aldea (Gema del Vino / Zamora 1912 - Salamanca 2012), académico y compañero, le dedicó un extenso In memoriam (Revuelta, 2012a). Destacó tanto su «Vida dedicada a la historia de la Iglesia» como su «Obra historiográfica». El detalle con que describe la formación y la actividad ministerial de Aldea, así como la precisión al recoger su producción científica revelan el conocimiento y aprecio que Revuelta tenía por Quintín ${ }^{19}$.

+ Compañero de tareas en la docencia e investigación en la Universidad Pontificia Comillas fue Rafael $\mathrm{M}^{\mathrm{a}}$ Sanz de Diego. Estos dos junto con José Ramón Eguillor, editaron las Memorias del P. Luis Martín, a las que más adelante nos referiremos. Rafa (como coloquialmente era conocido entre sus amigos y colegas), falleció inesperadamente en un accidente de tráfico el 29 de agosto 2015. Revuelta reaccionó con rapidez y el 1 de setiembre publicó una necrológica en el diario $A B C$ (Revuelta, 2015b) donde destaca sus facetas de jesuita, educador e historiador.

+ Compañero suyo fue también Luis Fernández Martín (Villameriel de Campos / Palencia 1908-Villagarcía de Campos 2003) (Revuelta, 2011a). Miembro de la Real Academia de la Historia, se centró en el estudio de la Edad Moderna ya en la última etapa de su vida.

+ Junto a estos contemporáneos suyos, Revuelta biografió también a Ignacio Casanovas Camprubí (Santpedor / Barcelona 1872-Barcelona 1936) uno de los grandes «ignacianistas» de la época contemporánea. Fundó la Biblioteca Balmes (1923) y compuso la Biblioteca d'Exercicis (1930-1936) (Revuelta, 2011f).

\section{c.2. Lingüistas y Literatos. Escritores}

+ Revuelta presentó a Eutimio Martino «como jesuita» en el homenaje que este recibió al cumplir sus 90 años. Historiador, profesor, filólogo... destacó por sus obras de carácter histórico y etnográfico y su pasión por la

18 Además de estos tres a los que recordó Revuelta, podemos nombrar, entre otros, a Miguel Batllori (1909-2003), Jesús Iturrioz (1909-1998), Quintín Aldea (19202012), Joaquín $M^{a}$ Domínguez (1924-), José Martínez de la Escalera (1921-2020), Francisco de Borja Medina (1925-).

19 Quintín Aldea fue numerario de la Real Academia de la Historia, editor del enorme Diccionario de Historia Eclesiástica de España (1972-1975. Madrid: CSIC [4 vols. + supl.]) y coordinador del monumental proyecto del Diccionario Biográfico Español (2011-2013. Madrid: Real Academia de la Historia [50 vols.]). 
filología, de manera especial por su afición a las etimologías y a la toponimia (Revuelta, 2015c).

+ Evocar la figura del P. Coloma (Jerez de la Frontera / Cádiz 1851 - Madrid 1915) es evocar una de las historias infantiles más entrañables de la literatura castellana: la del «Ratoncito Pérez» inserto en su obra Pequeñeces (1890-1891); «su mayor triunfo [...] reflejaba el ambiente de la aristocracia madrileña en los tiempos de Amadeo de Saboya y la Restauración». Coloma desempeñó la gran parte de su trabajo como escritor y editor en El Mensajero del Corazón de Jesús, primero en Bilbao (1885-1894) y después en Madrid (1894-1915). Revuelta dedicó a Coloma una breve biografía en una colaboración para la Asociación Española del libro Infantil y Juvenil (Revuelta, 2002).

+ Escritor propagandista y editor fue el P. Francisco de Paula Garzón (1850 Loja / Granada - 1950 Madrid). Fundó en 1890 la «Asociación del Apostolado de la Prensa» y a través de folletos de amplísima divulgación y publicaciones diversas expandía la doctrina católica frente a «ideas liberales» (Revuelta, 2001h, 1586 y 2011g).

\section{c.3. Paleontólogo}

Se trata del jesuita Valeriano Andérez (Mudas / Palencia 1905-Comillas / Cantabria 1954), profesor en Comillas (Cantabria) de ciencias naturales y antropólogo. La Diputación de Santander le puso al frente de la investigación de las cuevas de Juyo y Satián. Junto a su ciencia, Revuelta destaca su perfil humano «hombre sencillo, religioso observante y científico amante de la verdad y el trabajo» (Revuelta, 2001i, p. 159).

\section{c.4. Arabistas}

Félix María Pareja i Casañas (Barcelona 1890-Alcalá de Henares 1983) fue una personalidad muy original. Tras años de estudio en Zaragoza y Barcelona, recibió la ordenación sacerdotal en Heythrop College (Oxford), pronunció sus últimos votos en Beirut (1932), estudió teología en Beunos (Gales). Estudió sánscrito en Oxford (1929-1933). Fue profesor de árabe, persa y latín en St. Xavier College (Bombay / India) y más tarde, profesor de Islamología en la Universidad Pontificia Gregoria de Roma (1936-1939) (Revuelta, 2001j, p. 3.043).

\section{c.5. Orientalistas}

Santiago Morillo Treviño (Benquerencia/ Badajoz 1900-Madrid 1966) pasó unos años de su formación en Latinoamérica (Quito, 1925-La Paz, 
1926-28). Pero pidió ser destinado a la misión oriental de rito bizantino eslavo. Fue profesor en Dubno (entonces Ucrania polaca), en Bélgica y en Roma. «Hombre de temperamento atractivo y bondadoso llegó a dominar doce lenguas»(Revuelta, 2001k, p. 2.746 y 2013c).

\section{d. Directores espirituales / Formadores}

Otro pequeño centro de interés de Revuelta fueron los jesuitas que se dedicaron a ayudar a los más jóvenes de la orden en su formación y crecimiento como jesuitas.

+ Tal vez de los más conocidos fue el P. Manuel García Nieto (Macoteras / Salamanca 1894-Comillas / Cantabria 1974). Entró en la Compañía de Jesús cuando ya era sacerdote y después de una breve formación su único destino interrumpido por las vicisitudes de los tiempos de la Guerra Civil fue el centro de formación de Comillas / Cantabria donde se dedicó a la dirección espiritual de seminaristas y jóvenes jesuitas. "Todos coincidían en que era un santo que vivía intensamente lo que predicaba», comenta Revuelta para terminar: "cuando murió era voz común que había muerto un santo» (Revuelta, 2011h).

\section{e. Fundadores y directores de movimientos o congregaciones}

Otro tipo de formación y dirección espiritual era la que ejercían algunos jesuitas acompañando movimientos o congregaciones de religiosas o de laicos y laicas. Algunos de estos fueron fundados y promocionados por jesuitas de marcada y atractiva personalidad.

+ Ramón García Leal (1787 Cardona / Barcelona-1876 Poyanne / Francia) fue el fundador de La Corte de María «una asociación famosa cuyos socios se comprometían a visitar un santuario mariano una vez al mes» (Revuelta, 2001a, p. 1.574).

+ Revuelta define al P. Carlos Ferrís (Alba / Valencia 1856-Gandía / Valencia 1924) como "fundador de instituciones caritativas y sociales» y no le faltaba razón: «Fundó dos archicofradías piadosas, un instituto religioso femenino (terciarias de San Francisco de Asís y de la Inmaculada), un colegio de sordomudos y una residencia para universitarios [...] En 1892 fundó el Ropero [...] y en 1898 la Caja de Ahorros y Monte de Piedad de Gandía». Con todo, su fundación más importante fue la leprosería de Fontilles (19 de enero de 1909) (Revuelta, 2011i).

+ Junto con la joven salmantina Bonifacia Rodríguez de Castro, el P. Francisco Butiñá (Banyoles / Gerona 1834-Tarragona 1899) fundó el 7 de enero 
de 1874, la congregación de las religiosas Siervas de san José. A su regreso de Poyanne (Francia) fue destinado a la residencia de Girona y allí fundó la congregación de las Hijas de San José. Pese a que la intención de Butiñá era consolidar una única congregación, las Siervas y las Hijas no llegaron a unirse (Revuelta, 1988, pp. 318-319 y 403-404; 1999).

+ La vida del P. Mariano Cortés (Toledo 1812-Madrid 1869) ilustra también los vaivenes de aquellas generaciones de jesuitas que padecieron las expulsiones de uno y otro lugar. Revuelta sigue y persigue a sus biografiados con rigor y sistematicidad admirables. De Madrid, expulsado por el Conde de Toreno, el P. Cortés viajó (1836) a Vals-près-le-Puy (Francia). En el 39 regresó a Loyola de donde fue de nuevo expulsado y se dirigió a Suiza (1839-1841). En 1844 viajó desde París a Bogotá (113 días de viaje). En 1850 los jesuitas son expulsados de Colombia y regresó a Madrid. Allí fundó, junto con la Madre Sacramento, la Congregación de las Escuelas dominicales (1857) y más tarde en Zaragoza la de San Luis Gonzaga (1860). Las primeras estaban dedicadas a la formación de niñas pobres. Fue la obra de su vida (Revuelta, 2001m, p. 969 y 2011b).

+ Renovador y gran impulsor de las congregaciones marianas fue el P. Luis I. Fiter Cava (Seo de Urgel / Lérida 1852-Barcelona 1902). «Su obra resultó muy atractiva y formó figuras relevantes. La Congregación Mariana de Barcelona se consideró modélica en su género. Por su parte, Fiter fue reconocido como el restaurador de las congregaciones marianas» (Revuelta, 2011j)

\section{f. Misioneros populares y operarios}

La evangelización de las zonas rurales y pobres del interior de España fue otra de las misiones que la Compañía de Jesús acogió con dedicación y compromiso desde sus años más tempranos. Destacaron los nombres de Juan Conde, Francisco de P. Tarín o Tiburcio Arnáiz (Revuelta, 2005a).

+ Revuelta se fijó en la figura de Juan Conde Martín (Villarino de los Aires / Salamanca 1844-Lugo 1899). Tras diversos ministerios por Oña, Valladolid, Deusto y Comillas, se dedicó ya exclusivamente desde 1888 a las misiones populares. "Conde es uno de los misioneros más destacados, por el vigor de su oratoria y la resistencia que mostraba en sus trabajos, enlazando unas misiones con otras, en jornadas inagotables de sermones, conferencias y confesiones» (Revuelta, 2011k y 2005a).

+ Ignacio Santos (Fregeneda / Salamanca 1833-Valladolid 1908) fue compañero asiduo, primero, y biógrafo después de Juan Conde. Revuelta nos dice de él que «sus pláticas mesuradas y sencillas eran buen complemento de los fogosos sermones del P. Conde» y en cuanto a su personalidad «fue 
muy observante y celoso, diligente en el trabajo y certero en sus consejos» (Revuelta, 2001n, p. 3.504).

+ Recibe el nombre de "operario» el jesuita que se dedica a los ministerios sacerdotales. Félix López Soldado (Mondéjar / Guadalajara 1827-Madrid 1907) dedicó gran parte de su vida a visitar enfermos en hospitales o presos en las cárceles. Fundó el asilo del Niño Jesús y de san Martín. Fue también muy estimado como confesor y director espiritual. «Precursor del Apostolado de la Prensa, fundado por el P. Garzón» (Revuelta, 2001o, p. 2.419 y 2013d).

\section{g. Sociólogos}

En el Homenaje a los profesores historiadores de la Universidad Complutense José María Jover Zamora y Vicente Palacio Atard, Revuelta dedicó su contribución al jesuita Antonio Vicent (Castellón de la Plana 1837-Valencia 1912) enfatizando en el papel que la Reina María Cristina tuvo en su apoyo a los colegios de la Compañía (Revuelta, 1990) ${ }^{20}$. La contribución consiste en la publicación de una carta que el P. Vicent escribe al P. General Luis Martín el 23 de junio de 1897 desde el colegio san José de Valencia (pp. 560-565), precedida de una larga introducción en la que contextualiza cada uno de los puntos que Vicent desarrollará en su carta (pp. 547-560) y seguida de una documentación complementaria que el P. Vicent envió también a Roma (pp. 565-568. Cinco documentos) ${ }^{21}$. Revuelta volvió a trabajar sobre el P. Vicent en La Compañía de Jesús al hablar de «La acción social en la última década del siglo XIX» (Revuelta, 2008, pp. 718-738).

+ Revuelta dedicó dos trabajos monográficos de distinta envergadura al sociólogo Sisinio Nevares (Carrión de los Condes / Palencia 1878-Valladolid 1946). Encontramos en primer lugar una presentación general del P. Nevares en su entrada en el Diccionario Biográfico Español, (Revuelta, 2013a) pero ya ocho años antes, había publicado el extenso trabajo de 38 páginas centrado en la contribución del P. Nevares a los sindicatos agrarios palentinos (2005b). Como recoge en su entrada en el $D B E$, el P. Nevares se preocupó también por los sindicatos de Ferroviarios (1913) y de Mineros (1918). Fue el gran inspirador de la revista Fomento Social así como de la obra educativa que lleva su

20 Ya antes se había detenido Revuelta en este activo misionero de la acción social (véase Revuelta, 1984).

21 Imposible resumir aquí el contenido de esta valiosa carta en la que se describe la situación de los colegios de la Compañía de Jesús en la situación política del momento, buscando su reconocimiento oficial ante el Gobierno español. Documento, sin duda de enorme interés para la historia de la educación jesuítica española; publicada también en: Sanz de Diego, R. Mª (1980). 
nombre «Instituto Nevares de Empresarios Agrarios» (INEA-Valladolid), un sueño que «se hizo realidad después de su muerte» y que continúa en nuestros días como centro de referencia y de experiencias piloto e innovación en temas de agricultura y medioambiente.

\section{h. Gobierno}

Dentro de la compleja estructura que es la Compañía de Jesús, encontramos jesuitas que dedican gran parte de su vida a gestionar y organizar el funcionamiento interno de la propia institución, ocupando cargos de gobierno y liderazgo en diferentes niveles de la jerarquía (gobierno local, provincial, general). Revuelta reconoció a jesuitas con esta «misión» y sacó a la luz algunas de sus vidas. Como venimos viendo con los biografiados de Revuelta, casi todos ellos pertenecen al período histórico propio de su investigación. No obstante, encontramos algunos que se salen de los márgenes que podríamos considerar propios de la Época contemporánea.

+ Entre los numerosos prólogos que Revuelta escribió ${ }^{22}$, encontramos el que abre el libro sobre Juan Alfonso de Polanco (Burgos 1517-Roma 1576), calificado como uno de los "perdedores de la historia de España» ${ }^{23}$. No encontramos en la bibliografía de Revuelta otra mención a este importantísimo jesuita de la primera generación de la Compañía de Jesús y el gran arquitecto de su estructura institucional. El profundo conocimiento que Revuelta tenía de la figura de Ignacio de Loyola le había acercado algo más que «de oídas» a la persona de Polanco (Revuelta, 2012b) ${ }^{24}$.

+ Bajo el título "El último año de vida de la vida de Francisco de Borja» (Revuelta, 2001p) se esconde una nota, o como lo llama la revista Razón y $F e$, un "Comentario» al libro del Prof. Enrique García-Hernán La acción diplomática de Francisco de Borja al servicio del Pontificado (1571-1572). Este

22 Cf. Listado de Publicaciones. Revuelta, M. (2017b). Publicaciones..., 288-290, [nn. 208-238].

23 Evocamos así el título de F. García de Cortázar, Los perdedores de la historia de España (2006), en el que el historiador bilbaíno recoge las biografías de personajes españoles a los que la historia no ha hecho justicia, entre los que incluye al jesuita Juan Alfonso de Polanco (1517-1576), secretario y tantas otras cosas en la primera Compañía de Jesús.

${ }^{24}$ El prólogo es un valioso resumen de los principales contenidos del libro. Revuelta cree que con esta biografía se hace un «deber de justicia» a Polanco, tan desplazado a partir de la Congregación general III (1573). «Un héroe callado, de los que mueven los hilos de la historia sin ser vistos, de los que deciden cosas de importancia desde un segundo plano. Es de justicia reconocer los méritos de estos hombres discretos y leales» (p. 14). 
largo comentario da cuenta en la medida de lo posible, tanto del contenido del libro como del método empleado por el autor, al que Revuelta conocía en profundidad y valoraba enormemente como investigador. Un Borja «diplomático, lleno de humanidad. Es un Borja paciente, dialogante, conocedor de las limitaciones humanas, grande en su humildad» (p. 205).

Sobre este mismo personaje histórico y de este mismo historiador (García Hernán) tuvo Revuelta la ocasión de redactar una larga recensión al vol. VII de Monumenta Borgia (Revuelta, 2010) ${ }^{25}$, una colección de 1792 documentos correspondientes a la etapa de Borja como jesuita, de 1550 hasta su muerte en 1572. Siempre positivo, Revuelta termina su precioso análisis de este complejo volumen de Monumenta Borgia: «Enrique García Hernán merece los mayores elogios por el esmero que ha puesto en la edición de esta obra» (Revuelta, 2010, p. 466).

+ A Manuel Zúñiga (Alba de Tormes 1743-Madrid 1820) le tocó vivir todo el proceso de la expulsión de los jesuitas ordenada por Carlos III (1767) como el restablecimiento de la Orden en Roma en 1814 (Revuelta, 2001q, p. 4.087 y 2013e).

+ La breve biografía del P. Eugenio Labarta (Artajona / Navarra-Madrid 1807-1895) (Revuelta, 2001s) está atravesada por la enumeración de cargos que desempeñó a lo largo de toda su vida: Maestro de novicios, Superior, Prefecto, Consultor, Viceprovincial, Provincial. Muy finamente, Revuelta apunta: «tal vez se le tuvo más respeto que confianza» [...] llegó a ser el profeso más antiguo de toda la Compañía de toda la CJ».

+ Juan José de la Torre (Novales / Cantabria 1830-Madrid 1915) ocupó también los cargos de provincial y visitador de Centroamérica en estos tiempos difíciles. Renovó colegios y estructuras de formación. Fue también asistente de España (1883). Pero Revuelta destaca de él su faceta de historiador y pionero de la gran colección de las fuentes jesuíticas que habrían de ver la luz en la impresionante serie Monumenta Historica Societatis Iesu. «Destacó por su prudencia y tenacidad, así como por la compresión hacia sus súbitos» (Revuelta, 2001b, p. 2.247).

+ Contemporáneo de De La Torre fue el P. Tomás Ipiña (Elejabeitia 1844-Bilbao 1916). Loyola, León, Poyanne, La Habana, Woodstock, Poyanne, Carrión de los Condes, La Habana, Oña, Deusto, Salamanca, México, tercera vez en América, (1901-1913), para regresar a Bilbao hasta su muerte. La personalidad del P. Ipiña demuestra la capacidad de gente de este perfil para adaptarse a circunstancias, gestionar y decir con determinación, alentar,

25 El libro recensionado: García Hernán, E. (2009). Monumenta Borgia VII (15501566). Sanctus Franciscus Borgia quartus Gandiae dux et Societatis Iesu praepositus generalis tertius 1510-1572. 
impulsar. «Hombre afable y austero, "el dulce seco" como le llamaban los bilbaínos» (Revuelta, 2011m).

+ Tras ocho años de docencia de Psicología en Comillas (Cantabria), Antonio Encinas (Villarino de los Aires / Salamanca 1883-Comillas / Cantabria 1963). Recibió el «nombramiento de rector del colegio San José de Valladolid lo que significó para él — dice Revuelta- el comienzo de una etapa de veintiún años dedicados al gobierno con los siguientes cargos», rector en diversos colegios y provincial de León (1934-1940) (Revuelta, 2011n).

+ Dos veces provincial de España (1831-1844 y 1850-1852), Viceprovincial de los jesuitas españoles dispersos por Francia, el P. Antonio Morey «fue sin disputa el hombre más benemérito de la Compañía española en este tiempo y tal vez en todo el transcurrido desde su restablecimiento» (Revuelta, 2001r, p. 2.745).

+ Entre humanista y superior clasifica Revuelta a Francisco J. Baeza Torrecilla (Valladollid 1903-Valladolid 1994) (Revuelta, 2011o). Profesor de humanidades, rector de colegios y de la Universidad de Deusto y gran impulsor del Seminario de Comillas por Hispanoamérica. Provincial de Castilla, inauguró en 1959 la gran casa de Villagarcía de Campos.

+ Si bien he querido abrir este apartado dedicado a jesuitas entregados al gobierno de la Compañía de Jesús con Francisco de Borja, su tercer General, deseo terminarlo con otro General, el P. Luis Matín (Melgar de Fernamental / Burgos 1846-Roma 1906), vigésimo cuarto Prepósito General de la Orden. De entre las 482 de que consta el listado de «Publicaciones de Manuel Revuelta González», encontramos tres que se refieren directamente a este gran protagonista de la Compañía de Jesús contemporánea que fue el P. Luis Martín (Eguillor, Revuelta, Sanz de Diego, 1988).

Tanto por su extensión como por su valor histórico y rigor científico destacan las Memorias del P. Luis Martín, dos tomos de más de mil páginas cada uno presentados en una cuidada coedición a cargo de tres instituciones de la Compañía de Jesús. Revuelta mostró una especial simpatía y tal vez hasta admiración agradecida por el P. Luis Martín. Su interés por la historia y las decisiones que como General tomó para promover el estudio riguroso y la investigación sobre las fuentes y la historia de la Compañía de Jesús contribuyeron sin duda a despertar y promover este «afecto académico» por el P. Martín. De entre las varias iniciativas que promovió ${ }^{26}$, destaca, sin duda, el

26 Trasladó los archivos de la Compañía a Exaten (Holanda) para evitar una posible incautación por parte del gobierno italiano; alentó la publicación del Atlas Geographicus Socitatis Iesus (Luis Carrez); promovió la continuación de la enorme bibliografía comenzada por Charles Sommervogel (Bibliothèque de la Compagnie de Jésus) e impulsó la publicación de las Historias de las Asistencias cuyo resultado para 
comienzo de la publicación de Monumenta Historica Societatis Iesu (1894). El P. Martín comenzó a escribir sus Memorias en Roma en 1895 hasta lograr «un documento histórico excepcional» que llegó a tener unos 5.000 folios.

En su discurso de presentación de las Memorias en el mismo Melgar de Fernamental (31 de julio de 1988), Revuelta reconoce con sana humildad que «todos los especialistas que han manejado la edición de estas memorias han ponderado, por de pronto, el acierto que se ha tenido en la publicación de este documento como fuente histórica de valor excepcional» (Revuelta, 1998a, p. 97). Pero este entrañable documento de Revuelta, edificado sobre los sólidos cimientos de las Memorias, nos introduce en la personalidad del P. Martín a través de la relación con su pueblo («este noble pueblo», como Martín lo llamaba) y lo que significó para él a lo largo de su vida.

\section{APROXIMACIÓN A NO JESUITAS}

Aunque no me guste la definición por negación, Revuelta se ocupó también en menor medida de algunos personajes relevantes «no jesuitas».

+ Cuando uno se preguntaba si quedaría algo por decir sobre la vida de la Santa de Ávila, Revuelta se fijó en las tres estancias de Santa Teresa (Ávila 1515-Alba de Tornes 1582) en Palencia. Unía así dos temas muy queridos para él: la historia de la Iglesia, en este caso espiritualidad, y el afecto por su tierra natal Palencia (Revuelta, 2015a). El Prof. Teófanes Egido destaca en el prólogo el apoyo documental y las fuentes que Revuelta maneja en su libro: la bibliografía secundaria sobre el tema, los testigos que conocieron a la Madre Teresa (Gracián, Ana de san Bartolomé...) y, sobre todo, la fuente primera, el libro de Las Fundaciones escrito por la misma Santa Teresa.

+ Al caer dentro del período histórico de su investigación, Revuelta se encontró varias veces con la Madre Bonifacia Rodríguez de Castro (1837 Salamanca-1905 Zamora), fundadora junto con el P. Butiñá de la congregación de las Siervas de San José. Revuelta la define como «piadosa artesana» que acudía al confesionario del P. Butiñá en la clerecía de Salamanca. De esta relación surgió primero una Asociación de la Inmaculada y de san José que sería el germen de la futura fundación de las Siervas de san José (Revuelta, 1984, p. 319 y pp. 402-404; 2004).

España fue la gran obra de Antonio Astrain Historia de la Compañía de Jesús en la Asistencia de España (Madrid, 1902-1925) siete tomos de unas 800 páginas cada uno (cf. Sanz de Diego, R. M. (2001)). 
+ Por último, damos noticia de dos entradas en la Enciclopedia de Historia de España. Judas José Romo y Gamboa (1799-1855), obispo y cardenal (1850). Reaccionó abiertamente contra los ataques anticlericales de los liberales (Revuelta, 1991b). Fray Miguel de Santander (Santander 1744-Santa Cruz de Iguña / Cantabria 1831), religioso franciscano capuchino, obispo, predicador infatigable y escritor de pláticas, sermones y ejercicios espirituales (Revuelta, 1991c).

$$
* * *
$$

\section{EPÍLOGO}

Como filólogo aficionado a diccionarios y enciclopedias, la aportación de nuestro historiador Manuel Revuelta desde el género de «voz o entrada de diccionario" sobre personajes relevantes de la historia de la Compañía de Jesús, despertó hace meses mi «curiosidad científica». Desde entonces no he dejado de leer con satisfacción y asombro (parte de) la obra de Revuelta desde esta perspectiva personal y personalista que es la biografía.

Estas breves páginas han desvelado la capacidad de Revuelta para poner su mirada sobre tantos protagonistas que han ido construyendo la historia de España y que el tiempo, por pura inercia, ha ido silenciando. Son los «héroes callados» de las decisiones y de las obras muchas veces ensombrecidas pero que construyen el destino de personas e instituciones.

En su gran obra La Compañía de Jesús en la España contemporánea (Revuelta, 1984, 1991 a y 2008), Revuelta va incluyendo sus «dosis de biografía» en el lugar adecuado y momento oportuno. Así, al tiempo en que va exponiendo el contexto sociopolítico-eclesiástico en el que se desarrollan los acontecimientos en la convulsa España de finales del XIX, va intercalando también rostros y relatos de personas que otorgan humanidad y humanismo a la historia que nos ofrece.

Aproximarse a las biografías de Revuelta, pone también de manifiesto su extraordinaria capacidad de síntesis que, en medio de innumerables datos y con frecuencia una documentación inabarcable, sabe seleccionar y ofrecer al lector lo más preciso y esencial para redactar el mejor de los artículos.

Por último, y tal vez lo más importante, las biografías transparentan el estilo respetuoso y talante humano que Revuelta tenía a la hora de acercarse a sus personajes. Junto con una exquisita erudición en la que no falta jamás 
el dato necesario se entrevé la amabilidad del científico. Revuelta ha sabido transmitir también el perfil psicológico y espiritual de sus biografiados, con soltura, delicadeza y hasta con el fino humor que entre líneas reconocen aquellos que de su amistad y cercanía han disfrutado.

\section{REFERENCIAS}

Aa: (2001). Correspondencia. En O’Neill, Ch. - Domínguez, J. Ma (Dirs.). Diccionario Histórico de la Compañía de Jesús. Biográfico-Temático I. (pp. 965-969). RomaMadrid: Instituto Histórico de la Compañía de Jesús-Universidad Pontificia Comillas. (en adelante: $D H C J$ ).

Aixalá, J. (2001). 6. Catálogos (s.v. Correspondencia). DHCJ I, 967.

Eguillor, J.R., Revuelta, M. y Sanz de Diego, R. Ma (Eds.) (1988). Memorias del P. Luis Martín. General de la Compañía de Jesús (1846-1906). Tomo I (1846-1891). Tomo II (1891-1906). Roma-Madrid-Bilbao: Institutum Historicum Societatis Iesu-Universidad Pontificia Comillas-Universidad de Deusto-Mensajero.

García de Cortázar, F. (2006). Los perdedores de la historia de España. Barcelona: Planeta.

García Hernán, E. (2000). La acción diplomática de Francisco de Borja al servicio del Pontificado. Valencia: Generalitat Valenciana-Conselleria de Cultura, Educació i Ciència.

García Hernán, E. (2009). Monumenta Borgia VII (1550-1566). Sanctus Franciscus Borgia quartus Gandiae dux et Societatis Iesu praepositus generalis tertius 15101572. Valencia-Roma: Generalitat Valenciana - Institutum Historicum Societatis Iesu.

Gil, E. (1987). Publicaciones y actividad teológica de Gregorio Ruiz. Miscelánea Comillas 45, 251-258.

O’Neill, Ch. y Domínguez, J. Mª (2001). Diccionario Histórico de la Compañía de Jesús. Biográfico-Temático. Roma-Madrid: Instituto Histórico de la Compañía de Jesús-Universidad Pontificia Comillas.

Parker, G. (2015). Felipe II. La biografía definitiva. Barcelona: Planeta.

Real Academia de la Historia. (2011-2013). J. Olmedo y Q. Aldea (Eds.), Diccionario biográfico español. [versión digital]. Recuperado de http://www.dbe.rah.es.

Revuelta, M. (1973). Politica religiosa de los liberales en el siglo XIX. Trienio constitucional. Madrid: C.S.I.C.

Revuelta, M. (1976). La exclaustración (1833-1840). Madrid: BAC; reed. (2010). Madrid: CEU Ediciones.

Revuelta, M. (1979). La Iglesia Española ante la crisis del Antiguo Régimen (18081833). En R. García-Villoslada (Dir.), Historia de la Iglesia en España V. (pp. 3-113). Madrid: BAC.

Revuelta, M. (1984). La Compañía de Jesús en la España contemporánea. Tomo I. Supresión y reinstalación (1868-1884). Madrid: Sal Terrae-Mensajero-Universidad Pontificia Comillas. 
Revuelta, M. (1987). Perfiles humanos de Goyo. Miscelánea Comillas, 45, 240-243.

Revuelta, M. (1990). La Reina María Cristina y el P. Antonio Vicent. Problemas escolares y actitudes sociales durante la Restauración, vol. II. En Estudios históricos. Homenaje a los profesores José $M^{a}$ Jover Zamora y Vicente Palacio Atard. (pp. 547568). Madrid: Universidad Complutense.

Revuelta, M. (1991a). La Compañía de Jesús en la España contemporánea. Tomo II. La expansión en tiempos recios (1884-1906). Madrid: Sal Terrae-Mensajero-Universidad Pontificia Comillas.

Revuelta, M. (1991b). Romo y Gamboa, Judas José. En M. Artola (Dir.), Enciclopedia de Historia de España. Tomo IV. Diccionario biográfico. (p. 744). Madrid: Alianza editorial.

Revuelta M. (1991c). Santander, fray Miguel de., En M. Artola (Dir.), Enciclopedia de Historia de España. Tomo IV. Diccionario biográfico. (p. 777). Madrid: Alianza editorial.

Revuelta, M. (1992). El fundador de la Compañía. Historia 16, 191, 36-48.

Revuelta, M. (1993). Prólogo. En Echániz, I. El Hermano finuras. Beato Francisco Gárate, S.J. Bilbao: Mensajero.

Revuelta, M. (1998a). Las Memorias del P. Luis Martín y su relación con Melgar. En I. Guerrero López y A. López-Sanvicente (Coords.) Remembranzas de Homenaje al Rvdo. P. Luis Martín, SJ. (pp. 97-110). Burgos: Aldecoa.

Revuelta, M. (1998b). Los colegios de jesuitas y su tradición educativa (1868-1906). Madrid: Universidad Pontificia Comillas.

Revuelta, M. (1999). El P. Francisco Butiñá (1834-1899) en el contexto histórico de la Compañía de Jesús. Miscelánea Comillas, 57, 197-243.

Revuelta, M. (2001a). García Leal, Ramón. En En Ch. O’Neill y J. M ${ }^{\mathrm{a}}$ Dominguez (Dirs.), Diccionario Histórico de la Compañía de Jesús. II (p. 1574). Roma-Madrid: Instituto Histórico de la Compañía de Jesús-Univerisdad Pontificia Comillas. $(D H C J)$.

Revuelta, M. (2001b). La Torre, Juan José de. En DHCJ III, 2247-2248.

Revuelta, M. (2001c). Gil Sáenz, Manuel. En DHCJ II, 1729-1730.

Revuelta, M. (2001d). Gómez, Felipe. En DHCJ II, 1772.

Revuelta, M. (2001e). Maldonado, Carlos. En DHCJ III, 2483.

Revuelta, M. (2001f). Morán, Isacio María. En DHCJ III, 2738.

Revuelta, M. (2001g). Ruiz, Gregorio. En DHCJ IV, 3439.

Revuelta, M. (2001h). Garzón. Francisco de Paula. En DHCJ II, 1586.

Revuelta, M. (2001i). Andérez, Valeriano. En DHCJ I, 159.

Revuelta, M. (2001j). Pareja i Casañas, Félix. En DHCH IV, 3043.

Revuelta, M. (2001k). Morillo Treviño, Santiago. En DHCJ III, 2746.

Revuelta, M. (2001m). Cortés, Mariano. En DHCJ I, 969.

Revuelta, M. (2001n). Santos, Ignacio. En DHCJ IV, 3504.

Revuelta, M. (2001o). López Soldado, Félix. En DHCJ III, 2419-2420.

Revuelta, M. (2001p). El último año de Francisco de Borja. Razón y Fe, nº 243, 199205.

Revuelta, M. (2001q). Zúñiga, Manuel de. En DHCJ IV, 4087.

Revuelta, M. (2001r). Morey, Antonio. En DHCJ III, 2745.

Revuelta, M. (2001s). Labarta, Eugenio. En DHCJ III, 2249. 
Revuelta, M. (2002). El P. Luis Coloma (1851-1915). En Buscando a Ratón Pérez. Estudio del cuento infantil del P. Luis Coloma SJ. (pp. 13-27). Madrid: Asociación Española del Libro Infantil y Juvenil.

Revuelta, M. (2003). Un hombre santo en una España difícil. En Homenaje al Padre José María Rubio. (pp. 7-13). Madrid: Provincia de Toledo de la Compañía de Jesús.

Revuelta, M. (2004). Los jesuitas maestros espirituales de la beata Bonifacia Rodríguez. En V. López Luaces e I. Hernández Pérez (Coords.) Bonifacia Rodríguez de Castro. Centenario de su muerte (1905-2005). (pp. 27-40). Valladolid: Estudios josefinos.

Revuelta, M. (2005a). Gentes, paisajes y costumbres del norte de España en las crónicas de los misioneros populares. En F. Rivas y R. M. ${ }^{a}$ Sanz de Diego (Eds.), Iglesia de la historia. Iglesia de la fe. Homenaje a Juan María Laboa Gallego. (pp. 99-128). Madrid: Universidad Pontificia Comillas.

Revuelta, M. (2005b). El P. Sisinio Nevares. Etapas de su acción social y promoción de los sindicatos agrarios palentinos. Publicaciones de la Institución Tello Téllez de Meneses Palencia: 355-393.

Revuelta, M. (2006a). Once calas en la historia de la Compañía de Jesús. "Servir a todos en el Señor nuestro». Madrid: Universidad Pontificia Comillas.

Revuelta, M. (2006b). Influencias de san Ignacio en la Iglesia. XX Siglos, 17.

Revuelta, M. (2006c). «La vida de Ignacio. Fundamento de la historia de la Compañía». En Once calas en la historia de la Compañía de Jesús. "Servir a todos en el Señor». Madrid: Universidad Pontificia Comillas, 25-39.

Revuelta, M. (2008). La Compañía de Jesús en la España contemporánea. Tomo III. Palabras y fermentos (1868-1912). Madrid: Sal Terrae-Mensajero-Universidad Pontifica Comillas.

Revuelta, M. (2010). Monumenta Borgia VII (1550-1566). Miscelánea Comillas, 68, 463-366.

Revuelta, M. (2011a). Fernández Martín, Luis. En Diccionario Biográfico Español XIX. (p. 258). Madrid: Real Academia de la Historia (DBE).

Revuelta, M. (2011b). Cortés, Mariano. En DBE XIV, 760.

Revuelta, M. (2011c). Los ímpetus juveniles de Ignacio de Loyola y Francisco Javier. Alfa y Omega, 744 (28 de julio), 52.

Revuelta, M. (2011d). Basté Basté, Narciso. En DBE VII, 312.

Revuelta, M. (2011e). Basabe Terreros, Enrique. En DBE VII, 281.

Revuelta, M. (2011f). Casanovas Camprubí, Ignacio. En DEB XII, 139.

Revuelta, M. (2011g). Garzón, Francisco de Paula. En DBE, 536.

Revuelta, M. (2011h). García Nieto, Manuel. En DBE XXII, 128.

Revuelta, M (2011i). Ferris Vila, Carlos. En DBE XX, 24.

Revuelta, M. (2011j). Fiter Cava, Luis Ignacio. En DEB, 145.

Revuelta, M. (2011k). Conde Martín, Juan. En DBE XIV, 395.

Revuelta, M. (2011m). Ipiña, Tomás. En DEB XXVII, 307.

Revuelta, M. (2011n). Encinas, Antonio. En DEB XVII, 217.

Revuelta, M. (2011o). Baeza Torrecilla, Francisco Javier. En DBE VI, 526.

Revuelta, M. (2012a). Quintín Aldea, SJ. In memoriam. En Anuario de la Historia de la Iglesia 21, 534-538. 
Revuelta, M. (2012b). Prólogo. En García de Castro, J. (2012). Polanco. El Humanismo de los Jesuitas (1517-1576). Bilbao-Santander-Madrid: Mensajero-Sal TerraeUniversidad Pontificia Comillas.

Revuelta, M. (2013a). Nevares, Sisinio. En DBE XXXVII, 634.

Revuelta, M. (2013b). Ignacio de Loyola, una vida al servicio de la Iglesia. Palabra, 606, 68-69.

Revuelta, M. (2013c). Morillo Treviño, Santiago. En DBE, XXXVI, 452.

Revuelta, M. (2013d). López Soldado, FélIx. En DBE, XXX, 792.

Revuelta, M. (2013e). Zúñiga, Manuel de. En DBE L, 980.

Revuelta, M. (2015a). Las tres estancias de Santa Teresa en Palencia. Palencia: Institución Tello Téllez de Meneses.

Revuelta, M. (2015b, setiembre 1). «Rafa Sanz de Diego. Entregado con la docencia y con la historia», $A B C$. Recuperado de: https://www.abc.es/archivo/periodicos/ abc-madrid-20150901-56.html

Revuelta, M. (2015c). Eutimio, jesuita. En A. González Blanco (Ed.), Antigüedad y cristianismo. Monografías históricas sobre la antigüedad tardía. Toponimia e historia antigua. Homenaje al P. Eutimio Martino al cumplir 90 años. Murcia: Universidad de Murcia.

Revuelta, M. (2016). Prólogo. En C. Pasini. Nicolás de Bobadilla. Recuperación de un personaje de la primera Compañía de Jesús. (pp. 13-21). Bilbao-Santander-Madrid: Mensajero-Sal Terrae-Universidad Pontificia Comillas.

Revuelta, M. (2017a). Enigmas históricos de la Iglesia española contemporánea. Madrid: Universidad Pontificia Comillas.

Revuelta, M. (2017b). Publicaciones de Manuel Revuelta González. En Enigmas históricos de la Iglesia española contemporánea. (pp. 275-302). Madrid: Universidad Pontificia Comillas.

Sanz de Diego, R. M ${ }^{\mathrm{a}}$. (1980). El catolicismo social español ante la peregrinación obrera de 1894. Estudios Eclesiásticos, 55, 3-26.

Sanz de Diego, R. M. (2001). Astrain, Antonio. En DHCJ I, 258-259.

Schurhammer, G. O. (1992). Francisco Javier. Su vida y su tiempo. Bilbao: Mensajero. 


\section{LAS BIOGRAFÍAS DE REVUELTA ${ }^{27}$}

\begin{tabular}{|c|c|c|c|c|}
\hline $\begin{array}{l}\text { FECHAS } \\
\text { N-M }\end{array}$ & NOMBRE & DEDICACIÓN ${ }^{29}$ & $\begin{array}{c}\text { LUGAR } \\
\mathrm{N} / \mathrm{M}\end{array}$ & LOCALIZACIÓN \\
\hline 1844-1912 & ABAD, Matías & $\begin{array}{l}\text { Provincial } \\
\text { de Castilla }\end{array}$ & $\begin{array}{l}\text { Burgos / Deusto } \\
\text { (Bilbao) }\end{array}$ & $\begin{array}{l}\text { LCJEC II, } \\
600-603\end{array}$ \\
\hline $1852-1915$ & ADROER, Luis & $\begin{array}{l}\text { Provincial } \\
\text { de Aragón }\end{array}$ & $\begin{array}{l}\text { Viladesens } \\
\text { (Gerona) / } \\
\text { Gandía (Valencia) }\end{array}$ & $\begin{array}{l}\text { LCJEC II, } \\
5989-591\end{array}$ \\
\hline 1920-2012 & ALDEA, Quintín & Historiador & $\begin{array}{l}\text { Gema (Zamora) } \\
\text { / Salamanca }\end{array}$ & P. 191 \\
\hline 1905-1954 & $\begin{array}{l}\text { ANDÉREZ, } \\
\text { Valeriano }\end{array}$ & Paleontólogo & $\begin{array}{l}\text { Palencia / } \\
\text { Comillas } \\
\text { (Cantabria) }\end{array}$ & $\begin{array}{l}\text { P. } 250 . \text { DHCJ } \\
\text { I, } 159\end{array}$ \\
\hline 1903-1994 & $\begin{array}{l}\text { BAEZA } \\
\text { TORRECILLA, } \\
\text { Francisco J. }\end{array}$ & $\begin{array}{l}\text { Humanista } \\
\text { y superior }\end{array}$ & $\begin{array}{l}\text { Valladolid / } \\
\text { Valladolid }\end{array}$ & $\begin{array}{l}\text { P. 270. DBE, } \\
\text { VI, } 526\end{array}$ \\
\hline 1893-1977 & $\begin{array}{l}\text { BASABE } \\
\text { TERREROS, } \\
\text { Enrique }\end{array}$ & $\begin{array}{l}\text { Humanista y } \\
\text { benefactor }\end{array}$ & $\begin{array}{l}\text { Castro Urdiales } \\
\text { (Cantabria)/ } \\
\text { Salamanca }\end{array}$ & $\begin{array}{l}\text { P. 271. DBE, } \\
\text { VII, } 281\end{array}$ \\
\hline 1866-1936 & $\begin{array}{l}\text { BASTÉ BASTÉ, } \\
\text { Narciso }\end{array}$ & $\begin{array}{l}\text { Educador de } \\
\text { la juventud. } \\
\text { Mártir. Beato }\end{array}$ & $\begin{array}{l}\text { S. Andrés } \\
\text { de Palomar } \\
\text { (Barcelona) } \\
\text { / Valencia }\end{array}$ & $\begin{array}{l}\text { P. 272. DBE, } \\
\text { VII, } 312\end{array}$ \\
\hline $1509-1590$ & $\begin{array}{l}\text { BOBADILLA, } \\
\text { Nicolás de }\end{array}$ & $\begin{array}{l}\text { Cofundador de } \\
\text { la CJ. Profesor. }\end{array}$ & $\begin{array}{l}\text { Bobadilla } \\
\text { del Camino } \\
\text { (Palencia)/ } \\
\text { Loreto (Italia) }\end{array}$ & $\begin{array}{l}\text { P. 173. P. } 237 . \\
\text { DHCJ I, 463-465 }\end{array}$ \\
\hline 1834-1899 & BUTIÑÁ, Francisco & $\begin{array}{l}\text { Fundador } \\
\text { Siervas de } \\
\text { S. José }\end{array}$ & $\begin{array}{l}\text { Banyoles } \\
\text { (Gerona) / } \\
\text { Tarragona }\end{array}$ & P. 147 \\
\hline 1844-1919 & CAPELL, Juan & $\begin{array}{l}\text { Provincial } \\
\text { de Aragón }\end{array}$ & / Huesca & $\begin{array}{l}\text { LCJEC I, 668- } \\
\text { 672; II, 224-240 }\end{array}$ \\
\hline $1872-1936$ & $\begin{array}{l}\text { CASANOVAS } \\
\text { CAMPRUBÍ, } \\
\text { Ignacio }\end{array}$ & $\begin{array}{l}\text { Historiador } \\
\text { y escritor } \\
\text { espiritual }\end{array}$ & $\begin{array}{l}\text { Santpedor } \\
\text { (Barcelona) / } \\
\text { Barcelona }\end{array}$ & $\begin{array}{l}\text { P. 273. DBE, } \\
\text { XII, } 139\end{array}$ \\
\hline
\end{tabular}

27 Abreviaturas: DBE: Diccionario Biográfico Español; DHCJ: Diccionario Hitórico de la Compañía de Jesús; LCJEC: La Compañía de Jesús en la España Contemporánea; P: Publicaciones de Manuel Revuelta González.

28 Casi todas las palabras claves o expresiones que ofrezco en este apartado están tomadas de los artículos de diccionarios o de lo que el mismo Revuelta ofrece en LCJEC. Añado las que pretenecen a otras publicaciones. 


\begin{tabular}{|c|c|c|c|c|}
\hline $\begin{array}{l}\text { FECHAS } \\
\text { N-M }\end{array}$ & NOMBRE & DEDICACIÓN & $\begin{array}{l}\text { LUGAR } \\
\mathrm{N} / \mathrm{M}\end{array}$ & LOCALIZACIÓN \\
\hline $1851-1915$ & COLOMA, Luis & $\begin{array}{l}\text { Literato y } \\
\text { novelista }\end{array}$ & $\begin{array}{l}\text { Jerez de la } \\
\text { Frontera / Madrid }\end{array}$ & $\begin{array}{l}\text { P. } 59 \text { DHCJ } \\
\text { I, } 860-861 \\
\end{array}$ \\
\hline 1848-1899 & $\begin{array}{l}\text { CONDE } \\
\text { MARTÍN, Juan }\end{array}$ & $\begin{array}{l}\text { Misionero } \\
\text { popular }\end{array}$ & $\begin{array}{l}\text { Villarino } \\
\text { de los Aires } \\
\text { (Salamanca) / } \\
\text { Quiniril (Lugo) }\end{array}$ & $\begin{array}{l}\text { P. 274. DBE, } \\
\text { XIV, } 395\end{array}$ \\
\hline $1812-1889$ & CORTÉS, Mariano & $\begin{array}{l}\text { Operario. Fund. } \\
\text { de las Escuelas } \\
\text { Dominicales }\end{array}$ & $\begin{array}{l}\text { Torre de S. } \\
\text { Esteban (Toledo) } \\
\text { / Madrid }\end{array}$ & $\begin{array}{l}\text { P. } 251 . \text { DHCJ } \\
\text { I, } 969 \text { y P. } 275 . \\
\text { DBE, XIV, } 760\end{array}$ \\
\hline $1826-1894$ & $\begin{array}{l}\text { DELGADO, } \\
\text { Agustín }\end{array}$ & $\begin{array}{l}\text { Provincial } \\
\text { de Toledo }\end{array}$ & $\begin{array}{l}\text { Almodóvar del } \\
\text { Campo (C. Real) } \\
\text { / Jerez de la } \\
\text { Frontera (Cádiz) }\end{array}$ & $\begin{array}{l}\text { LCJEC I, 672- } \\
676 ; \text { II, 251-254. }\end{array}$ \\
\hline $1883-1963$ & ENCINAS, Antonio & $\begin{array}{l}\text { Superior y } \\
\text { educador. }\end{array}$ & $\begin{array}{l}\text { Villarino } \\
\text { de los Aires } \\
\text { (Salamanca) } \\
\text { / Comillas } \\
\text { (Cantabria) }\end{array}$ & $\begin{array}{l}\text { P. 276. DBE, } \\
\text { XVII, } 217\end{array}$ \\
\hline $1908-2003$ & $\begin{array}{l}\text { FERNÁNDEZ } \\
\text { MARTIIN; Luis }\end{array}$ & Historiador & $\begin{array}{l}\text { Villameriel } \\
\text { de Campos } \\
\text { (Palencia)/ } \\
\text { Villagarcía } \\
\text { de Campos } \\
\text { (Valladolid) } \\
\end{array}$ & $\begin{array}{l}\text { P. } 277 \text {. DBE, } \\
\text { XIX, } 258\end{array}$ \\
\hline 1856-1924 & $\begin{array}{l}\text { FERRÍS VILAS, } \\
\text { Carlos }\end{array}$ & $\begin{array}{l}\text { Predicador. } \\
\text { Fundador } \\
\text { instituciones } \\
\text { caritativas }\end{array}$ & $\begin{array}{l}\text { Albal (Valencia) / } \\
\text { Gandía (Valencia) }\end{array}$ & $\begin{array}{l}\text { P. 278. DBE, } \\
\mathrm{XX}, 24\end{array}$ \\
\hline $1852-1902$ & $\begin{array}{l}\text { FITER CAVAS, } \\
\text { Ignacio }\end{array}$ & $\begin{array}{l}\text { Director de la } \\
\text { Congregación } \\
\text { mariana }\end{array}$ & $\begin{array}{l}\text { Seo de Urgel } \\
\text { (Lérida) / } \\
\text { Barcelona } \\
\end{array}$ & $\begin{array}{l}\text { P. } 279 . \text { DBE, } \\
\text { XX, } 145\end{array}$ \\
\hline 1572 & $\begin{array}{l}\text { FRANCISCO } \\
\text { DE BORJA }\end{array}$ & $\begin{array}{l}\text { General de la } \\
\text { CJ. Santo }\end{array}$ & $\begin{array}{l}\text { Gandía (Valencia) } \\
\text { / Roma }\end{array}$ & P. 156 \\
\hline $1506-1552$ & $\begin{array}{l}\text { FRANCISCO } \\
\text { JAVIER }\end{array}$ & $\begin{array}{l}\text { Misionero. } \\
\text { Santo }\end{array}$ & $\begin{array}{l}\text { Javier (Navarra) } \\
\text { / Shangchuan } \\
\text { (China) }\end{array}$ & P. 187 \\
\hline 1857-1929 & $\begin{array}{l}\text { GÁRATE, } \\
\text { Francisco }\end{array}$ & $\begin{array}{l}\text { Hermano, } \\
\text { portero. Beato }\end{array}$ & $\begin{array}{l}\text { Azpeitia } \\
\text { (Guipúzcoa) / } \\
\text { Deusto (Bilbao) }\end{array}$ & P. 216 \\
\hline $1789-1876$ & $\begin{array}{l}\text { GARCÍA LEAL, } \\
\text { Ramón }\end{array}$ & $\begin{array}{l}\text { Fundador de la } \\
\text { Corte de María }\end{array}$ & $\begin{array}{l}\text { Barcelona } \\
\text { / Poyanne } \\
\text { (Francia) }\end{array}$ & P. DHCJ II, 1574 \\
\hline
\end{tabular}




\begin{tabular}{|c|c|c|c|c|}
\hline $\begin{array}{l}\text { FECHAS } \\
\text { N-M }\end{array}$ & NOMBRE & DEDICACIÓN & $\begin{array}{c}\text { LUGAR } \\
\mathrm{N} / \mathrm{M}\end{array}$ & LOCALIZACIÓN \\
\hline 1894-1974 & $\begin{array}{l}\text { GARCÍA NIETO, } \\
\text { Manuel }\end{array}$ & $\begin{array}{l}\text { Director } \\
\text { espiritual }\end{array}$ & $\begin{array}{l}\text { Macotera } \\
\text { (Salamanca) } \\
\text { / Comillas } \\
\text { (Cantabria) }\end{array}$ & $\begin{array}{l}\text { P. 280. DBE, } \\
\text { XXII, } 128\end{array}$ \\
\hline $1850-1919$ & $\begin{array}{l}\text { GARZÓN, Fco. } \\
\text { De Paula }\end{array}$ & $\begin{array}{l}\text { Editor, } \\
\text { periodista, } \\
\text { apologeta }\end{array}$ & Granada / Madrid & $\begin{array}{l}\text { P. } 252 . \text { DHCJ II, } \\
1586 \text { y P. } 280 . \\
\text { DBE XXII, } 536\end{array}$ \\
\hline $1794-1880$ & GIL SÁEZ, Manuel & $\begin{array}{l}\text { Profesor y } \\
\text { Superior }\end{array}$ & Madrid / Fiésole & $\begin{array}{l}\text { P. 253. DHCJ } \\
\text { II, } 1730\end{array}$ \\
\hline $1811-1870$ & GÓMEZ, Felipe & $\begin{array}{l}\text { Profesor y } \\
\text { Superior }\end{array}$ & Cáceres / Madrid & $\begin{array}{l}\text { P. 255. DHCJ } \\
\text { II, } 1772\end{array}$ \\
\hline $1848-1917$ & $\begin{array}{l}\text { GRANERO, Juan } \\
\text { de la Cruz }\end{array}$ & $\begin{array}{l}\text { Provincial } \\
\text { de Toledo }\end{array}$ & $\begin{array}{l}\text { Granada / } \\
\text { Granada }\end{array}$ & $\begin{array}{l}\text { LCJEC II, } \\
615-620\end{array}$ \\
\hline $1858-1942$ & $\begin{array}{l}\text { IBERO, Ignacio } \\
\text { María }\end{array}$ & $\begin{array}{l}\text { Provincial } \\
\text { de Castilla }\end{array}$ & $\begin{array}{l}\text { Azpeitia } \\
\text { (Guipúzcoa) } \\
\text { / Loyola }\end{array}$ & $\begin{array}{l}\text { LCJEC II, } \\
607-609\end{array}$ \\
\hline $1491-1556$ & $\begin{array}{l}\text { IGNACIO DE } \\
\text { LOYOLA }\end{array}$ & $\begin{array}{l}\text { Fundador } \\
\text { de la CJ. }\end{array}$ & Loyola / Roma & $\begin{array}{l}\text { P. 14, 129, } \\
187,195\end{array}$ \\
\hline $1851-1933$ & IÑIESTA, Antonio & $\begin{array}{l}\text { Provincial } \\
\text { de Aragón }\end{array}$ & $\begin{array}{l}\text { Mogente } \\
\text { (Valencia) / } \\
\text { Valencia }\end{array}$ & $\begin{array}{l}\text { LCJEC II, } \\
591-594\end{array}$ \\
\hline $1844-1916$ & IPIÑA, Tomás & $\begin{array}{l}\text { Formador y } \\
\text { Superior }\end{array}$ & $\begin{array}{l}\text { Castillo de } \\
\text { Elejabeitia } \\
\text { (Vizcaya) / Bilbao }\end{array}$ & $\begin{array}{l}\text { P. 282. DBE, } \\
\text { XXVII, } 307 .\end{array}$ \\
\hline 1837-1905 & \begin{tabular}{|l} 
JESUITAS Y \\
BONIFACIA RGZ \\
DE CASTRO \\
\end{tabular} & $\begin{array}{l}\text { Religiosa y } \\
\text { fundadora }\end{array}$ & $\begin{array}{l}\text { Salamanca } \\
\text { / Zamora }\end{array}$ & P. 67 \\
\hline $1830-1915$ & $\begin{array}{l}\text { LA TORRE, } \\
\text { Juan José de }\end{array}$ & $\begin{array}{l}\text { Provincial } \\
\text { de Castilla } \\
\text { y escritor }\end{array}$ & $\begin{array}{l}\text { Novales } \\
\text { (Cantabria) } \\
\text { / Madrid }\end{array}$ & $\begin{array}{l}\text { P. 258. DHCJ } \\
\text { III, 224. LCJEC } \\
\text { I, 654-657 }\end{array}$ \\
\hline $1807-1895$ & LABARTA, Eugenio & Superior & $\begin{array}{l}\text { Artajona } \\
\text { (Navarra)/ } \\
\text { Madrid }\end{array}$ & $\begin{array}{l}\text { P. 257. DHCJ } \\
\text { III, } 2249\end{array}$ \\
\hline $1827-1907$ & $\begin{array}{l}\text { LÓPEZ } \\
\text { SOLDADO, Félix }\end{array}$ & $\begin{array}{l}\text { Operario y } \\
\text { catequista }\end{array}$ & $\begin{array}{l}\text { Mondéjar } \\
\text { (Guadalajara) } \\
\text { / Madrid }\end{array}$ & $\begin{array}{l}\text { P. 259. DHCJ } \\
\text { III, 2419-20; y } \\
\text { P. 283. DBE, } \\
\text { XXX, 79-8 }\end{array}$ \\
\hline $1827-1907$ & $\begin{array}{l}\text { LÓPEZ } \\
\text { SOLDADO, Félix }\end{array}$ & $\begin{array}{l}\text { Editor y } \\
\text { catequista }\end{array}$ & $\begin{array}{l}\text { Macotera } \\
\text { (Salamanca) } \\
\text { / Comillas } \\
\text { (Cantabria) }\end{array}$ & $\begin{array}{l}\text { P. 283. DBE, } \\
\text { XXX, 79-80 }\end{array}$ \\
\hline
\end{tabular}




\begin{tabular}{|c|c|c|c|c|}
\hline $\begin{array}{l}\text { FECHAS } \\
\text { N-M }\end{array}$ & NOMBRE & DEDICACIÓN & $\begin{array}{l}\text { LUGAR } \\
\mathrm{N} / \mathrm{M}\end{array}$ & LOCALIZACIÓN \\
\hline $1816-1872$ & $\begin{array}{l}\text { MALDONADO, } \\
\text { Carlos }\end{array}$ & $\begin{array}{l}\text { Profesor de } \\
\text { Teología }\end{array}$ & $\begin{array}{l}\text { Ciudad Real / } \\
\text { Maryland (USA) }\end{array}$ & $\begin{array}{l}\text { P. 260. DHCJ } \\
\text { III, } 2483\end{array}$ \\
\hline 1846-1906 & MARTÍN, Luis & $\begin{array}{l}\text { Provincial de } \\
\text { Castilla, General } \\
\text { de la CJ }\end{array}$ & $\begin{array}{l}\text { Melgar de } \\
\text { Fernamental } \\
\text { (Palencia) / Roma }\end{array}$ & P. 35.53 P. 152 \\
\hline 1925- & $\begin{array}{l}\text { MARTINO, } \\
\text { Eutimio }\end{array}$ & $\begin{array}{l}\text { Lingüista y } \\
\text { filólogo }\end{array}$ & & P. 204 \\
\hline $1879.1-58$ & $\begin{array}{l}\text { MORÁN, } \\
\text { Isacio María }\end{array}$ & $\begin{array}{l}\text { Director } \\
\text { espiritual y } \\
\text { profesor }\end{array}$ & $\begin{array}{l}\text { Valladolid / } \\
\text { Oña (Burgos) }\end{array}$ & $\begin{array}{l}\text { P. 261. DHCJ } \\
\text { III, } 2738\end{array}$ \\
\hline 1794-1856 & MOREY, Antonio & Superior & $\begin{array}{l}\text { Palma de M. } \\
\text { / Palma de } \\
\text { Mallorca }\end{array}$ & $\begin{array}{l}\text { P. } 262 . \text { DHCJ } \\
\text { III, } 2745\end{array}$ \\
\hline 1900-1966 & $\begin{array}{l}\text { MORILLO } \\
\text { TREVIÑO, } \\
\text { Santiago }\end{array}$ & $\begin{array}{l}\text { Orientalista } \\
\text { y profesor }\end{array}$ & Badajoz / Madrid & $\begin{array}{l}\text { P. 263. DHCJ } \\
\text { III, 2746 y } \\
\text { P. 284. DBE, } \\
\text { XXXVI, } 452\end{array}$ \\
\hline 1842-1895 & $\begin{array}{l}\text { MURUZÁBAL, } \\
\text { Fco. De Sales }\end{array}$ & Superior & Navarra / Bilbao & $\begin{array}{l}\text { P. 264. DHCJ } \\
\text { III, } 2775-786\end{array}$ \\
\hline 1842-1887 & $\begin{array}{l}\text { MURUZABAL, } \\
\text { Francisco de Sales }\end{array}$ & $\begin{array}{l}\text { Provincial } \\
\text { de Castilla y } \\
\text { de Toledo }\end{array}$ & $\begin{array}{l}\text { S. Martín de } \\
\text { Unx (Navarra) / } \\
\text { Deusto (Bilbao) }\end{array}$ & $\begin{array}{l}\text { LCJEC I,664- } \\
\text { 667; II, 245-247 }\end{array}$ \\
\hline 1878-1946 & $\begin{array}{l}\text { NEVARES } \\
\text { MARCOS, Sisinio }\end{array}$ & Sociólogo & $\begin{array}{l}\text { C. de los Condes } \\
\text { (Palencia)/ } \\
\text { Valladolid }\end{array}$ & $\begin{array}{l}\text { P. 171. DHCJ } \\
\text { III, 2814 y } \\
\text { P. 285. DBE, } \\
\text { XXXVI, } 634\end{array}$ \\
\hline 1860-1919 & $\begin{array}{l}\text { PAGASARTUNDÚA, } \\
{\text { José } \mathrm{M}^{\mathrm{a}}}\end{array}$ & $\begin{array}{l}\text { Provincial } \\
\text { de Toledo }\end{array}$ & Madrid / Madrid & $\begin{array}{l}\text { LCJEC II, } \\
622-626\end{array}$ \\
\hline 1890-1983 & $\begin{array}{l}\text { PAREJA I } \\
\text { CASAÑAS, Félix M }\end{array}$ & Arabista & $\begin{array}{l}\text { Barcelona / } \\
\text { Alcalá de Henares }\end{array}$ & $\begin{array}{l}\text { P. 265. DHCJ } \\
\text { III, } 3043\end{array}$ \\
\hline $1517-1576$ & $\begin{array}{l}\text { POLANCO, Juan } \\
\text { Alfonso de }\end{array}$ & $\begin{array}{l}\text { Historiador, } \\
\text { gestor, teólogo }\end{array}$ & Burgos / Roma & P. 232 \\
\hline 1838-1916 & RICART, Juan & $\begin{array}{l}\text { Provincial } \\
\text { de Aragón }\end{array}$ & $\begin{array}{l}\text { Vich (Barcelona) } \\
\text { / Barcelona }\end{array}$ & $\begin{array}{l}\text { LCJEC II, } \\
240-245\end{array}$ \\
\hline $1793-1857$ & $\begin{array}{l}\text { RODRÍGUEZ } \\
\text { DE CARASA, } \\
\text { Eduardo J. } \\
\end{array}$ & $\begin{array}{l}\text { Director } \\
\text { espiritual }\end{array}$ & Cádiz / Madrid & $\begin{array}{l}\text { P. 266. DHCJ } \\
\text { IV, 3396-97 }\end{array}$ \\
\hline 1773-1855 & $\begin{array}{l}\text { ROMO Y } \\
\text { GAMBOA, Judas }\end{array}$ & $\begin{array}{l}\text { Eclesiástico, } \\
\text { historiador } \\
\text { y escritor }\end{array}$ & $\begin{array}{l}\text { Cañizares } \\
\text { (Guadalajara) / } \\
\text { Umbrete (Sevilla) }\end{array}$ & P. 241 \\
\hline
\end{tabular}




\begin{tabular}{|c|c|c|c|c|}
\hline $\begin{array}{l}\text { FECHAS } \\
\text { N-M }\end{array}$ & NOMBRE & DEDICACIÓN & $\begin{array}{c}\text { LUGAR } \\
\mathrm{N} / \mathrm{M}\end{array}$ & LOCALIZACIÓN \\
\hline $1864-1929$ & RUBIO, José M ${ }^{\mathrm{a}}$ & $\begin{array}{l}\text { Santo, Apóstol } \\
\text { de Madrid y } \\
\text { operario }\end{array}$ & $\begin{array}{l}\text { Dalías (Almería) } \\
\text { / Aranjuez } \\
\text { (Madrid) }\end{array}$ & P.64. \\
\hline $1937-1986$ & $\begin{array}{l}\text { RUIZ GONZÁLEZ, } \\
\text { Gregorio (Goyo) }\end{array}$ & $\begin{array}{l}\text { Escriturista } \\
\text { y profesor }\end{array}$ & $\begin{array}{l}\text { Aguilar de } \\
\text { Campoo } \\
\text { (Palencia) } \\
\text { / Dueñas } \\
\text { (Palencia) }\end{array}$ & $\begin{array}{l}\text { P. 115. } 267 . \\
\text { DHCH IV, } 3439\end{array}$ \\
\hline $1744-1831$ & $\begin{array}{l}\text { SANTANDER, } \\
\text { Fray Miguel de }\end{array}$ & $\begin{array}{l}\text { Franciscano, } \\
\text { predicador, } \\
\text { misionero }\end{array}$ & $\begin{array}{l}\text { Santander / } \\
\text { Santander }\end{array}$ & P. 242 \\
\hline $1833-1908$ & SANTOS, Ignacio & $\begin{array}{l}\text { Misionero } \\
\text { popular }\end{array}$ & $\begin{array}{l}\text { Fregeneda / } \\
\text { Valladolid }\end{array}$ & $\begin{array}{l}\text { P. 268. DHCJ } \\
\text { IV, } 3504\end{array}$ \\
\hline $1940-2015$ & \begin{tabular}{|l} 
SANZ DE \\
DIEGO, Rafael
\end{tabular} & $\begin{array}{l}\text { Profesor e } \\
\text { historiador }\end{array}$ & $\begin{array}{l}\text { Madrid / Alcázar } \\
\text { de San Juan }\end{array}$ & P. 202. \\
\hline $1515-1582$ & $\begin{array}{l}\text { TERESA DE } \\
\text { JESÚS }\end{array}$ & $\begin{array}{l}\text { Religiosa, } \\
\text { Fundadora } \\
\text { carmelita }\end{array}$ & $\begin{array}{l}\text { Ávila / Alba } \\
\text { de Tormes } \\
\text { (Salamanca) }\end{array}$ & P. 19. \\
\hline $1861-1906$ & VIGO, Jaime & $\begin{array}{l}\text { Provincial } \\
\text { de Aragón y } \\
\text { de Toledo }\end{array}$ & Gerona / Madrid & $\begin{array}{l}L C J E C \text { II, 586- } \\
589 \text { y } 620-622\end{array}$ \\
\hline $1822-1887$ & $\begin{array}{l}\text { VIGORDÁN, } \\
\text { Ramón }\end{array}$ & $\begin{array}{l}\text { Provincial } \\
\text { de Aragón }\end{array}$ & $\begin{array}{l}\text { Granén (Huesca) } \\
\text { / Tortosa } \\
\text { (Tarragona) }\end{array}$ & $\begin{array}{l}\text { LCJEC I, 657- } \\
664 ; \text { II, 254-258 }\end{array}$ \\
\hline $1837-1912$ & VINCENT, Antonio & $\begin{array}{l}\text { Pionero social } \\
\text { en España }\end{array}$ & $\begin{array}{l}\text { Castellón de la } \\
\text { Plana / Valencia }\end{array}$ & $\begin{array}{l}\text { P. 41. DHCJ } \\
\text { IV, 3937-3939 }\end{array}$ \\
\hline $1847-1919$ & ZAMEZA, Isidro & $\begin{array}{l}\text { Provincial } \\
\text { de Castilla }\end{array}$ & $\begin{array}{l}\text { Vizcaya / Oña } \\
\text { (Burgos) }\end{array}$ & $\begin{array}{l}\text { LCJEC II, } \\
603-607\end{array}$ \\
\hline $1743-1820$ & ZÚÑIGA, Manuel & $\begin{array}{l}\text { Restaurador de } \\
\text { la C.J. en España }\end{array}$ & $\begin{array}{l}\text { Alba de Tormes } \\
\text { (Salamanca) } \\
\text { / Madrid }\end{array}$ & $\begin{array}{l}\text { P. 269. DHCJ } \\
\text { IV, 4087-4088 } \\
\text { y P.286. DBE, } \\
\text { L, 980; }\end{array}$ \\
\hline
\end{tabular}

